\title{
Consumers Response to a New Food Safety Issue: Food Terrorism ${ }^{1}$
}

\author{
Kinsey, J.D., Stinson T.F., Degeneffe D.J., Ghosh K., and Busta, F.F. ${ }^{2}$
}

\begin{abstract}
Deliberate contamination of some component of the food supply with the intention of doing physical or economic harm or creating fear (terror) defines food terrorism. Food is one of several vectors used to induce intense prolonged fear with imagined or real future dangers. It has been used around the world. Witness such examples as 1978 mercury in Jaffa oranges in five European countries, 1984 salmonellae in a salad bar in the U.S., 2003 rat poisoning in school breakfasts in China. More than four thousand U.S. consumers were surveyed to ascertain their level of concern about food defense measures relative to food safety and their preferences for allocating resources to defend the food system compared to defending other infrastructure such as airlines, public transportation or national monuments. Contrary to actual food defense expenditures, consumers indicated that $13 \%$ more should be allocated to food systems than to airlines. Twenty-six percent were not confident the food supply is safe; $55 \%$ were not confident the food supply is secure. Segmenting the representative sample into archetypes, based on attitudes, shows that those who have a high fear level as well as those who are risk averse allocated the most to defending food. Food defense has become another factor in the quest for safe food consumption. Consumers are more concerned about food terrorism than food safety.
\end{abstract}

Corresponding author:

Jean D. Kinsey

2168 Ferris Lane

Roseville, MN 55113

jkinsey@umn.edu

\footnotetext{
1 . Research conducted at The Food Industry Center, University of Minnesota. This research was supported by the U.S. Department of Homeland Security (Grant number N-00014-04-1-0659), through a grant awarded to the National Center for Food Protection and Defense at the University of Minnesota. Any opinions, findings, conclusions, or recommendations expressed in this publication are those of the author(s) and do not represent the policy or position of the Department of Homeland Security.

${ }^{2}$ J. D.Kinsey, Department of Applied Economics and The Food Industry Center; T.F. Stinson, Department of Applied Economics; D.J. Degeneffe and K. Ghosh, The Food Industry Center; F.F. Busta, the National Center For Food Protection and Defense; all at the University of Minnesota, St. Paul, MN.
} 


\title{
Consumers Response to a New Food Safety Issue: Food Terrorism
}

\author{
Kinsey, J.D., Stinson T.F., Degeneffe D.J., Ghosh K., and Busta, F.F.
}

\section{Introduction}

Deliberate contamination of some component of the food supply with the intention of doing physical or economic harm or creating fear (terror) defines food terrorism. Food is one of several vectors used to induce intense prolonged fear with imagined or real future dangers. It has been used around the world. Witness such examples as 1978 mercury in Jaffa oranges in five European countries, 1984 salmonellae in a salad bar in the U.S., 2003 rat poisoning in school breakfasts in China (Kennedy \& Busta, 2006). In this century terrorism of all types has heightened awareness, spawned research into new technologies to detect and decontaminate, and intensified protection and defense protocols in food plants. Consumers are beneficiaries of increased security measures but are also victims of fear, and potentially physical harm.

Food defense refers to activities that protect an already safe food supply from deliberate contamination with the intent to cause catastrophic physical harm or death to many people and/or to create an economic disaster to the food industry by causing it to stop production and sale of food for an extended period of time. Food safety traditionally deals with the accidental or natural contamination of food with some agent that makes people ill or may lead to death. The agents of concern are innate pathogenic microorganisms and their proliferation pathways. Food defense deals with the deliberate contamination of food with unfamiliar agents that typically cause high mortality rates.

Consumers in the United States as well as much of the rest of the world have come to expect that the food they purchase to eat is safe to eat. Good manufacturing practices, food safety regulations and inspections, and the protection of private brand names all conspire to provide food that can generally be considered safe to eat. Keeping food and the food supply chain safe is the business of those involved in food protection and defense. It is increasingly the business of every food producer, manufacturer, distributor and retailer.

\section{Consumer Behavior Theory}

Psychologists know that consumers willingly accept high levels of risk voluntarily but are loath to be subjected to risk and uncertainty that is involuntary (Lowrance,1976; Kuchler and Golan, 2006). Classic examples are the general acceptance of a high risk of injury and death from driving an automobile compared to outrage and anger over the low risk of a dread disease like cancer. The low risk of being harmed by a terrorist attack on the food system which is totally out of the control of individual consumers and something they and their loved ones could be subjected to involuntarily leads to more fear and outrage than more familiar hazards.

Behavioral economic theories predict that consumers are willing to pay more to prevent a loss than to obtain a gain (Kaheman and Tversky, 1979). Consumers generally consider their food 
supply to be safe. It is something they take for granted in most countries and for their food to be contaminated deliberately would be considered a great loss. Therefore, we would expect consumers to be willing to pay more to prevent these types of losses than to gain an increment of food safety.

Becker and Rubinstein (2005) found that those who are frequent users and/or have a large investment in using a product were less likely to be intimidated or to stop using the product after a terrorist attack. This is also consistent with the voluntary nature of product use and the differentiation between gains and losses. For example, airline pilots whose livelihood depends on flying are less likely to stop flying than the casual vacationer. The pilot has salary to gain by returning to the airplane; the vacationer perceives to potential loss and finds alternative modes of transportation. Likewise, consumers must eat food to live (ultimately an involuntary but familiar act) so the contamination risks that accompany this act are involuntarily received. Being harmed by eating deliberately contaminated food is an involuntary risk and therefore more fearsome than a risk taken voluntarily (like flying). When it comes to allocating funds to protect against terrorist attacks, one would expect that consumers would allocate more to protect against attacks on food than airlines on the basis of behavioral theory.

\section{Research on Consumer Attitudes and Preferences}

A large survey of U.S. consumers' attitudes and concerns about terrorism in the United States was conducted over the Internet in the first week of August, 2005. The survey, funded by the National Center for Food Protection and Defense was designed to elicit the relationship between consumers' levels of fear and preferences for allocating funds against the protection and defense of the food system relative to airlines and other potential terrorist targets. Responses were obtained from 4260 U.S. residents over the age of 16, and then weighted by age, race and ethnic origin, sex, income, and geographic region to reflect the characteristics of the national population. Respondents were asked how likely they believed each of six different types of attacks to be and about their perceptions of the physical, economic, psychological and emotional damage each type of act would inflict on the country and on them personally. The separate terrorist acts covered by the survey were another aircraft hijacking, an incident involving some other form of public transportation, destruction of a national monument, deliberate contamination of the food supply, disruption of the power grid, and release of a chemical or biological agent in a public area.

To provide a further indication of the relative concern U.S. residents attach to different types of terrorist attacks, respondents also were asked how they believed anti-terrorist spending should be allocated among the potential types of targets. The exact wording of the question was "For every $\$ 100$ that you think should be spent to protect the country from terrorism, how would you divide it across the following types of attacks? Enter a dollar amount for each. The amounts must sum up to \$100." The choices given-another attack using a passenger aircraft, attack on other public transportation, destruction of a national monument, deliberate chemical of biological contamination of a common food product, disruption of the electrical power grid, release of a biological or chemical agent in a crowded public area, and other-were randomized across survey respondents with the exception that the passenger aircraft and other public transportation alternatives were always paired and other was always the last option. Asking respondents to divide $\$ 100$ among specific types of terrorism risks, 
rather than construct a contingent valuation, willingness-to-pay, question has the advantage of being readily understood and simple to respond to. It obtains a preference ranking, indeed a percentage measure, for the allocation of finite resources. This type of question was designed after conducting four focus group studies to determine how consumers can readily rank and "price" the value of reducing various types of terrorism risk.

It should be noted that the $\$ 100$ was not specified as public or private spending. It must be recognized that some of the total spending to protect and defend the food supply, as well as other potential terrorist targets, will be from private companies, some from individual consumers taking precautionary measures and some from public (government) agencies. The average percentage allocations obtained provide a measure of the relative intensity of concern over different types of terrorism. The percentage allocations can also be used to provide a crude estimate of the amount the public believes should be spent on anti-terrorist activity by comparing them against the known level of system.

\section{Consumers Preferences for Allocations to Defense}

Most respondents to the survey believe further terrorist attacks will occur in the relatively near future. At least one act of terrorism within the next four years (after August 2005) is expected by 95 percent of the public (Table 1). Differences in the perceived probabilities of attacks within four years are relatively small, but the differences between pairs of terrorist acts all were statistically significant except for those between release of a chemical or biological agent in a public area and disruption of the power grid. After possible attacks on trains or subways are excluded, nearly 81 percent of the public expect at least one terrorist incident during the next four years. An attack on the food system is thought least likely, but still 44 percent of U.S. residents expect an attempt to introduce a toxin into the food supply chain within the four years following the survey.

Table 1: Percentage of U.S. Residents Expecting a Terrorist Attack within the Next Four Years, by Type of Attack, August, 2005

\begin{tabular}{ll}
\hline Attack Target & Percent \\
\hline Passenger aircraft & 53 \\
Public transportation & 84 \\
$\begin{array}{l}\text { Destruction of a national monument } \\
\text { Deliberate chemical or biological }\end{array}$ & 49 \\
$\begin{array}{l}\text { contamination of a common food } \\
\begin{array}{l}\text { Disruption of the power grid } \\
\text { Release of a chemical or biologic agent in a } \\
\text { crowded public area }\end{array}\end{array}$ & 44 \\
\hline
\end{tabular}

Survey respondents were asked how they believed the nation's anti-terrorism budget should be divided to protect against different types of terrorist attacks. Despite their belief that other types of terrorism are more likely in the near future, the public believes the implications of an attack on the food system so serious that a greater percentage of anti-terrorism spending 
should be allocated to protecting the food supply than to defending any other potential target among the choices offered (Table 2).

Table 2: Percentage of Anti-terrorism Spending United States Residents Believe Should Be Allocated to Protecting against Particular Types of Terrorist Attacks, by Type of Terrorist Attack, August, 2005.

\begin{tabular}{|c|c|c|}
\hline Attack Target & Percent & $\begin{array}{l}\text { Percent of } \\
\text { aircraft } \\
\text { Spending }\end{array}$ \\
\hline Passenger aircraft & 16.88 & 100.0 \\
\hline Public transportation & 17.06 & 101.1 \\
\hline Destruction of a national monument & 8.16 & 48.3 \\
\hline $\begin{array}{l}\text { Deliberate chemical or biological } \\
\text { contamination of a common food }\end{array}$ & 19.13 & 113.3 \\
\hline Disruption of the power grid & 14.97 & 88.7 \\
\hline $\begin{array}{l}\text { Release of a chemical or biologic agent in a } \\
\text { crowded public area }\end{array}$ & 18.90 & 112.0 \\
\hline Other & 4.91 & 29.1 \\
\hline
\end{tabular}

On average U.S. residents believe that more than 19 percent of the resources that should be spent to protect against terrorism should be spent to defend the food supply chain. Protecting against release of a chemical or biological agent in a public area is also seen as a high priority receiving almost the same percentage allocation as protecting the nation's food supply system.

The public believes that about 17 percent of the anti-terrorism budget should be spent to secure subways and railways and just less than 17 percent to protect airline transportation. Preventing disruption of the power grid was allocated 15 percent of the anti-terrorism budget while 8 percent would go to preventing destruction or damage to a national monument and 5 percent to preventing other forms of terrorism.

The percentage allocations chosen for spending to protect against each different type of attack are all significantly different from zero. Differences between the public's allocations for activities to protect the food supply chain or to protect against potential chemical and biological attacks and the percentage of the anti-terrorism budget that should go for protecting air transportation are also significantly different at the 95 percent level.

When the percentage allocations of the homeland security budget indicated by the public are converted to spending levels as a percentage of the amount believed appropriate to provide secure air transportation, U.S. residents indicate they would allocate 13.3 percent more for protecting the food supply than for protecting airline travel. Preventing a chemical or biological attack was given 12 percent more, and protecting other transportation activities 1 percent more than preventing an aircraft hijacking.

\section{Food Terrorism Allocations After Education (Post Scenario)}


Once respondents had made an initial distribution of funds for defending against possible terrorist activities a scenario describing the progression of events following a potential food terrorism incident was introduced.

"Emergency room visits and hospital admissions suddenly increase in the region where you live. A foodborne toxin is suspected to be the cause. The number of individuals affected continues to grow over the next several days and some of those hospitalized die. Similar patterns are seen in other metropolitan areas within the region. The number of fatalities associated with this problem grows. State and national agencies struggle to identify the source of the problem. Ten days after the first report a statement is issued by a government agency saying that there has been a deliberate attempt to contaminate the food system. By comparing the pattern of affected consumers and the distribution of various types of food products a single commonly used food product has been identified as the source. It is estimated that more than 50,000 units of the contaminated product have already been purchased. Consumers are instructed to bring all unused product to central collection sites for disposal. Ultimately the death toll from this incident reaches $1500 . "$

After reading the above scenario the survey respondents were again asked to allocate resources to combat terrorism. Differences between the naïve and post-scenario results are shown in table 4.

Table 4: United States Residents Percentage Allocation of Anti-terrorism Budget, by Type of Attack, Naïve and Post Scenario Allocations, August, 2005.

\begin{tabular}{|c|c|c|c|}
\hline Attack Target & $\begin{array}{l}\text { Percent } \\
\text { (Naïve) }\end{array}$ & $\begin{array}{l}\text { Percent } \\
\text { (Post- } \\
\text { Scenario) }\end{array}$ & $\begin{array}{l}\text { Change in } \\
\text { percentage } \\
\text { points }\end{array}$ \\
\hline Passenger aircraft & 16.88 & 15.48 & $(1.4)$ \\
\hline Public Transportation & 17.06 & 16.39 & $(0.7)$ \\
\hline Destruction of a national monument & 8.16 & 7.84 & $(0.3)$ \\
\hline $\begin{array}{l}\text { Deliberate chemical or biological } \\
\text { contamination of a common food }\end{array}$ & 19.13 & 22.88 & 3.75 \\
\hline Disruption of the power grid & 14.97 & 14.41 & $(0.6)$ \\
\hline $\begin{array}{l}\text { Release of a chemical or biologic agent } \\
\text { in a crowded public area }\end{array}$ & 18.90 & 18.77 & $(0.1)$ \\
\hline Other & 4.91 & 4.24 & $(0.7)$ \\
\hline
\end{tabular}

As anticipated, the proportion of anti-terrorism spending that respondents believe should go to protect the food supply system increases substantially. Post-scenario responses call for programs protecting the food system to receive nearly 23 percent of all anti-terrorism spending, 3.75 percentage points more than before being informed of the potential consequences of an act of food terrorism. Protecting against release of a chemical or biological agent in a crowded public area remains the second highest priority and the proportion of the anti-terrorist budget that should be devoted to that mission remains almost constant, falling by just over 0.1 percentage points. 
The proportion or resources devoted to protecting against airline hijacking fell by the largest amount, down 1.4 percentage points. Allocations to protecting other transportation systems, national monuments, the power grid, and other uses also fell, but by smaller amounts. All allocations in the post scenario responses are significantly different from the airline allocation, and the allocations for each potential terrorist target changes significantly from the naïve responses except for release of a chemical or biological agent in a crowded public area. Post-Scenario allocations primarily take funds away form airline security and allocate them to food security.

Women, African Americans, and individuals with a high school education or less, show the largest increases in the proportion of spending they believed should be devoted to protecting the food supply after being exposed to additional information. African Americans and individuals residing in the East and West South Central States reduce the proportion of spending they believed should go to secure the airways by more than the national average, while men and college graduates reduce their allocation for that activity by less than the national average. There were relatively small differences in the changes in resources that were thought appropriate for the other anti-terrorist activities (Stinson et. al, 2006).

\section{Food Defense and Food Safety}

Concerns and the relative allocation of funds to food safety was determined as well as food defense. Since there is a long history of food safety programs and expenditures, this provides a useful benchmark for the priority consumers give to food defense. Soliciting concern about both food safety and defense reveals that 49 percent of respondents were very concerned (checked 5 or 6 on a 6 point scale) about food defense but only 29 percent were very concerned about food safety even though there is a significant correlation between the two overall. In contrast, almost one-third were very confident about food safety and only 12 percent were very confident about food defense. Again there is a significant correlation between the two. In general people are more confident about food safety and less concerned about it than they are about food defense. This might be expected since we have become accustomed to safe food and food defense is a new concept and new fear.

A key question asked respondents to allocate $\$ 100$ between food safety and food defense. On average they allocated $\$ 52$ to food safety with $\$ 48$ to food defense. Two thousand one hundred and sixty respondents split the allocation fifty-fifty. Of the 28 percent who allocated more to food safety than food defense, compared to the 22 percent who allocated more to food defense, there was tendency to have a higher level of education, be from an Asian ethnic group, be a middle aged single person, and to have more confidence in food safety than food defense.

When asked who should be responsible for food safety and food defense there was little distinction across parties in the food supply chain from farmers to consumers, but eight percentage points more thought that government should be responsible for food defense (53 percent) than food safety (45 percent). Food manufacturers and the government were selected as the parties that should bear the greatest share of the cost for both food safety and food defense with 21-23 percent respectively, saying food manufacturers or processors should bear the costs and 24-28 percent respectively, saying the government should bear the cost.. Clearly there is a belief and understanding that costs are borne by both public and private parties. 
Communicating with the public in a food safety or food defense crisis is an important part of planning for damage control. Most of the consumers (82-84 percent) want to receive information about how they can protect themselves during a food safety or food defense crisis. In a food defense crisis three-quarters of the respondents want information about the scope and significance of the crisis and 65 percent want to know who was responsible. When asked the source and amount of information they would like to receive in a food safety crisis the highest ranked source was a tie between television and medical/public health officials followed by the Internet, another tie between newspapers and officials from private companies involved, and then federal officials. The information sources ranked lowest were religious leaders and university experts.

\section{Segmented Archetypes}

Segmentation has long been a marketing research method used by private industry to identify consumer segments. Marketers have deployed successful business strategies by focusing on the needs of specific groups of consumers in the development of meaningful new products, and highly effective advertising campaigns. In the context of food defense it can provide food companies with an indication of the importance their consumers place on measures to protect their food from deliberate contamination and institute protective measures to meet consumers expectations. This same research approach can be applied in the public sector research for providing government agencies and policy makers with a tool for better understanding the diversity of consumer needs and developing more effective programs and communications.

The segmentation approach used a battery of 75 consumer attitude/value statements which was developed from a set of similar questionnaires used in the private sector by marketing research companies, and findings from a set of focus groups conducted for the purpose of questionnaire development for this study. The range of statements was intentionally very broad and general so as to enable the identification of fundamental consumer values that relate to an individual's sense of security/vulnerability in relationship to a potential terrorist attack. These statements included such dimensions as: lifestyle, outlook on life, aspirations, fears, views of authority, self image, health orientation, family focus, sense of social responsibility and moral standards. In the development of this battery of statements, each of these dimensions is believed to have some relevance to a person's concern over potential terrorist attacks. A balanced six point Likert scale was used so as to enable some degree of discrimination without a neutral point. Respondents were asked their degree of agreement as to whether the statement described them with anchor points of "strongly agree" (6) to "strongly disagree" (1). The first 5 items on this list of statements is listed in Figure 1 below.

Other measures used in the segmentation analysis includes concerns over different types of terrorist targets, expectations for the timing of potential attacks, and the allocation of defense spending by potential target. These measures were used as a set of "result" measures (dependent variables) in a factor analysis to identify relationships between individual attitude/value measures and orientation to terrorist attacks. The results of factor analysis provided the basis for collapsing the 75 attitudinal statements into a manageable number of clusters. These clusters (segments) and the dependent variables were used in canonical analysis to determine how each segment is related to dependent variables such as the allocation of $\$ 100$ to various types of terrorist attacks. Once the segments were identified, all 
other questions in the questionnaire were used to describe the profile and characteristics the people in each segment. These segments can be thought of as archetypes of consumers.

Figure 1

\begin{tabular}{|l|l|}
\hline $\begin{array}{l}\text { Q- } \\
14\end{array}$ & $\begin{array}{l}\text { Please indicate how much you agree or disagree with each of the following } \\
\text { statements by using the 6 point scale where "1 " means you " Strongly Agree", and } \\
\text { "6" means you "Strongly Disagree." Please circle the number you think best } \\
\text { describes you. }\end{array}$ \\
\end{tabular}

\begin{tabular}{|c|c|c|c|c|c|}
\hline \multirow[t]{2}{*}{ Attitude/Values/Lifestyle Battery } & \multicolumn{5}{|c|}{ for Each } \\
\hline & Strongly & & & & Strongly \\
\hline I like the challenge of doing something I have & & & & & \\
\hline never done before & 1 & 3 & 4 & 5 & 6 \\
\hline I like trying new things & 1 & 2 & 4 & 5 & 6 \\
\hline I often crave excitement & 1 & 2 & 4 & 5 & 6 \\
\hline I would like to spend a year or more in a & & & & & \\
\hline foreign country & 1 & 2 & 4 & 5 & 6 \\
\hline $\begin{array}{l}\text { Everyone has the power to be successful if they } \\
\text { just work hard }\end{array}$ & 1 & 2 & 4 & 5 & 6 \\
\hline
\end{tabular}

Indexes are used extensively to explain the findings and to make comparisons across archetypes relative to the total sample of citizens. For most scaled questions, these indexes are based on the percent of respondents who answered in the "top two boxes" of the rating scale - either a 6 or a 5. For example, the percent of respondents who marked a 5 or 6 on the attitude statements in Figure 1 would be the "score" for that statement. The index is then computed as the "score" for the archetype in segment one divided by the "score" for the total sample on the same statement.

For all differences sited in the analysis, a significance test was done on the mean (not the "top two box score" or the index) difference between the segment and the total sample. Unless otherwise noted all differences are significant at .95 or higher.

\section{Segments Found}

Six consumer segments were identified. These segments were studied with respect to the pattern of attitude/value statement responses and named based on the analyst's (D. Degeneffe) net impression about the attitude/value mindset expressed by each respective segment. (Other names could apply.) These segments vary in size from the largest Predestinarians at $19.9 \%$ of the general population over the age of 16 - to the smallest "Principled \& Self-Disciplined" at $13.6 \%$ of the general population over the age of 16 . The segments and their relative sizes are shown in Figure 2. The differences in size are not dramatic, suggesting that each segment represents an appreciable proportion of the general population. Therefore, it is important to understand and address each segment equally in the development of policies and strategies to mitigate the impact of potential terrorist attacks. 


\section{Segment Profiles Described}

\section{Segment 1}

The "Uncommitted C'est la vie" tend not to worry about the unexpected and believe that health threats they have heard about in the news are overblown. Relative to the general population (and other segments) they can be characterized as having low levels of concern over health and safety. The "Uncommitted C'est la vie" attitude also carries over to social interactions. They are less likely to worry about how others view them, and have yet to set any goals for their career or life.

The demographic profile of the "Uncommitted C'est la vie" helps put some of these attitudes in perspective. Although this segment includes people of all ages, there is greater tendency for The "Uncommitted C'est la vie" to be between 16 and 24 years of age, and male. Therefore, the attitude/value set likely reflects young adulthood, and a time before social, family and career commitments force one's attention to uncertainties and risks.

\section{Figure 2: Size of Segments}

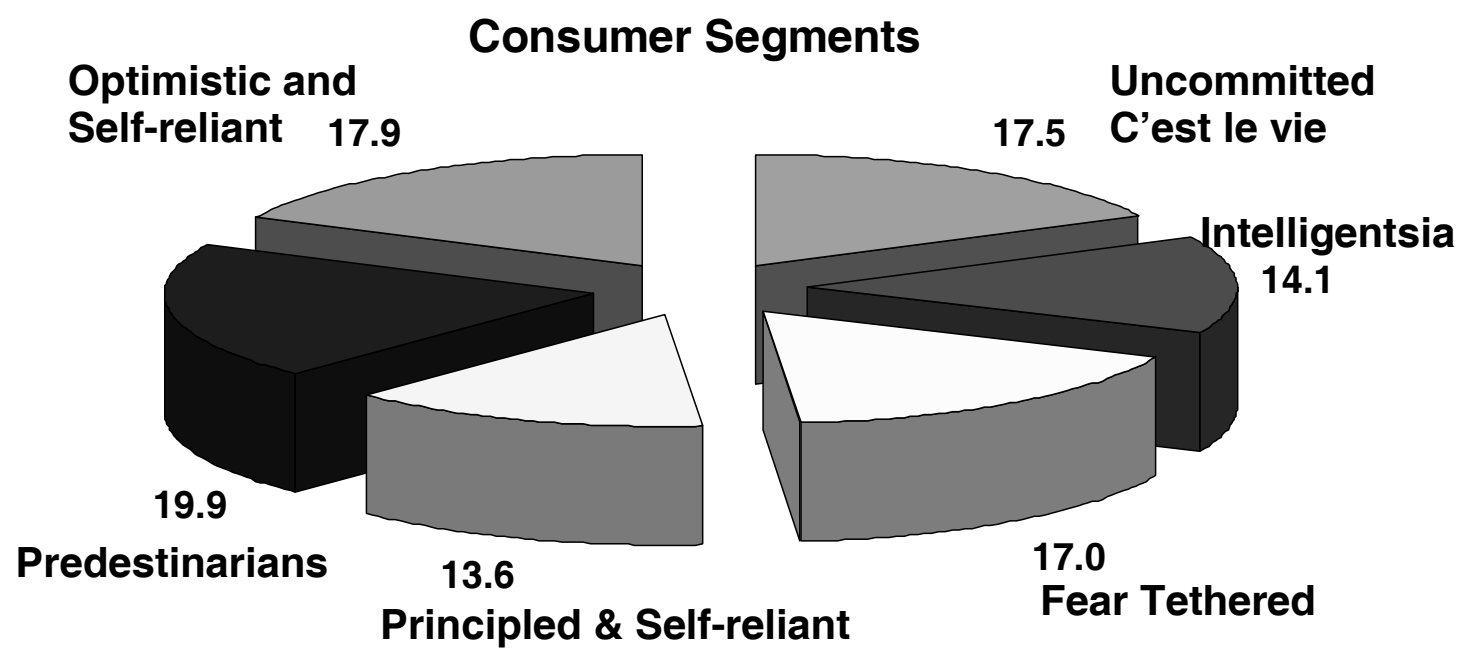

The "Uncommitted C'est la vie" are not likely to be concerned over the threat of terrorist attack, and are not likely to prepare for it. In the event of an attack they probably would be caught off guard, and experience a sense of helplessness. However they are more likely to have only themselves to look out for.

\section{Segment 2}

The "Intelligentsia" hunger for learning and experience. They value freedom of action and thought, and tend to question authority. The "Intelligentsia" view themselves as more knowledgeable than most people, and use this knowledge to gain the admiration of others. They are status seekers, but more from an intellectual standpoint than a material standpoint. The knowledge they accumulate gives the "Intelligentsia" the sense that they are more in tune with reality. Therefore, they tend to be more concerned over health and security threats, as well as environmental risks. 
The most notable demographic characteristic of the "Intelligentsia" is education level. They are more likely to have a bachelors degree from college, or higher. They are nearly $50 \%$ more likely than the general population to have a post graduate degree. Also they tend to be older $-50+$ years of age, male and live in 1-2 member households. Clearly the education levels attained by the "Intelligentsia,"are consistent with the attitudes and values they express.

When it comes to terrorism, the "Intelligentsia" will already have an awareness if not a sense of fear over the potential for attacks. Their biggest concerns with be with respect to credibility of the source of information.

\section{Segment 3}

The "Fear Tethered" is the citizen segment with the greatest fear level in general, as well as with respect to terrorist attack. They have a much greater tendency than the general population, (and other segments) to be frightened by the threat of disease, and threats to personal and family safety. This fear seems to emanate from a sense of powerlessness, such that "Fear Tethered" sense little control or influence over future events. Still they do have strong values and convictions. Family, religion, social conscious and the environment are all important. Further, they express a sense of ambition and set career/life goals. In a sense the "Fear Tethered" manage their own affairs as best they can, but feel that they are at the mercy of dangerous forces beyond their control.

From a demographic standpoint, the "Fear Tethered" tend to have family responsibilities. They have a higher tendency (than the general population) to be between the ages of 30 and 44 , to be female, and have $3+$ member households. They also tend to be moderately educated with high school diplomas to associate college degrees.

Clearly the attitudes/values of the "Fear Tethered" emanate from their focus on the welfare of their family. They readily interpret the risks they hear about in the media to be risks to themselves and their family, and this results in fear and apprehension. In preparing them for a real terrorist event, the need will be to provide them with objective factual information and a sense for how they can do what is most important, namely protect their family.

\section{Segment 4}

The "Principled \& Self-Disciplined" can be best characterized as risk avoiders. They deal with future uncertainty by planning and self discipline - they maintain a budget and set aside money for major purchases, they maintain a healthy and balance diet, and, they plan for the future, and have insurance policies in place. As a result, the "Principled \& Self-Disciplined" have an optimistic view of the future. Their principles are also reflected in other ways. They view others as inherently good, and have a strong social conscience, with a sense of responsibility for the welfare of society, and the natural environment. Still, from a moral standpoint they are conservative with strong personal integrity and religious convictions. "Principled \& Self-Disciplined are practical and pragmatic people, and are less into the superficial - e.g. trends and fashions, adventure, or needing the admiration of others. 
From a demographic standpoint "Principled \& Self-Disciplined" are generally average, but do tend to be older than the general population - the strongest skew is $50+$ years of age. Additionally they have a slight tendency to be white, female, and living in 2 person households.

The "Principled and Self-Disciplined' would likely be highly receptive to communications on how to prepare for the possibility of a terrorist attack. They would likely follow the advice of a credible spokesperson. And in the event of an attack would likely maintain a level head, and be willing to volunteer and help others.

\section{Segment 5}

"Predestinarians" are generally supporters of the status quo, believing that future events are predestine to occur. They trust in the country's leadership, and are optimistic toward the future, expecting that things will not be that different from the past. Therefore, they are less likely to be concerned over safety or sickness, and are less likely to plan for the future. "Predestinarians" are the most morally conservative group, with a tendency to have fundamental religious convictions, and hold strong beliefs regarding gender roles. Still they consider material wealth as being important, and are trend/fashion conscious. Demographically, "Predestinarians" are much more likely than the general population to be under the age of 40, and have be moderately educated - high school diploma to associates college degree. They also tend to have incomes under $\$ 40,000$, and live in rural and small metro areas. Also, relative to the general population, "Predestinarians" have a higher incidence of minority groups - Hispanic, Black/African American, Asian and Native American.

With "Predestinarians" tending to trust the country's leadership they are likely to rely on the government to protect and care for citizens in the event of an attack.

\section{Segment 6}

The "Optimistic \& Self-Reliant" are likely to be highly involved in building careers and accumulating wealth. They are successful in life, and prefer to assume leadership roles. They have financial plans, and are optimistic toward the future. Therefore, they are fairly contented with life and are less likely to share the fears and anxieties of other segments.

Not surprisingly, the "Optimistic \& Self-Reliant" segment has the highest socio-demographic skew. They are more likely to have incomes over $\$ 60,000$, and are twice as likely to have incomes over $\$ 100,000$. They tend to be more educated, and live in larger population centers. Age (25-45) tends to reflect the career development lifestage.

With respect to security from terrorism, the "Optimistic \& Self-Reliant" are not likely to have invested much attention or thought. Careers are more likely to have taken a priority.

\section{Concern over Terrorism by Segment}

Level of concern over terrorism varies dramatically across the segments.

Respondents were asked to indicate how concerned they are about six alternative terrorist events. The event that received the highest level of concern in the overall sample was an attack on public transportation (other than airlines). For this type of attack, $88 \%$ of the "Fear 
Tethered" segment indicated either a 5 or a 6 on the six point scale which contrasts sharply with a score of only $28 \%$ among the "Uncommitted C'est la vie." The top two box score over concern for an attack on public transportation (other than airlines) varied across the other segments as follows: "Principle \& Self-Disciplined" 76\%, "Intelligentsia" 69\%, "Predestinarians" 54\% and "Optimistic \& Self-Reliant" 52\%. Similar patterns in levels of concern were seen across the other five types of terrorist events.

Allocation of $\$ 100$ to defend the various types of terrorist target against an attack varied some across the archetypes. Figure 3 identifies the different al locations. The importance of these allocations is that it is a surrogate of consumers' preferences and ranking of concerns. This information can be very useful to those making decisions about how to divide up scarce resources related to food protection and defense.

\section{Figure 3.}

\section{Allocation of Funds Across Various Types of Terrorism by Archetype.}

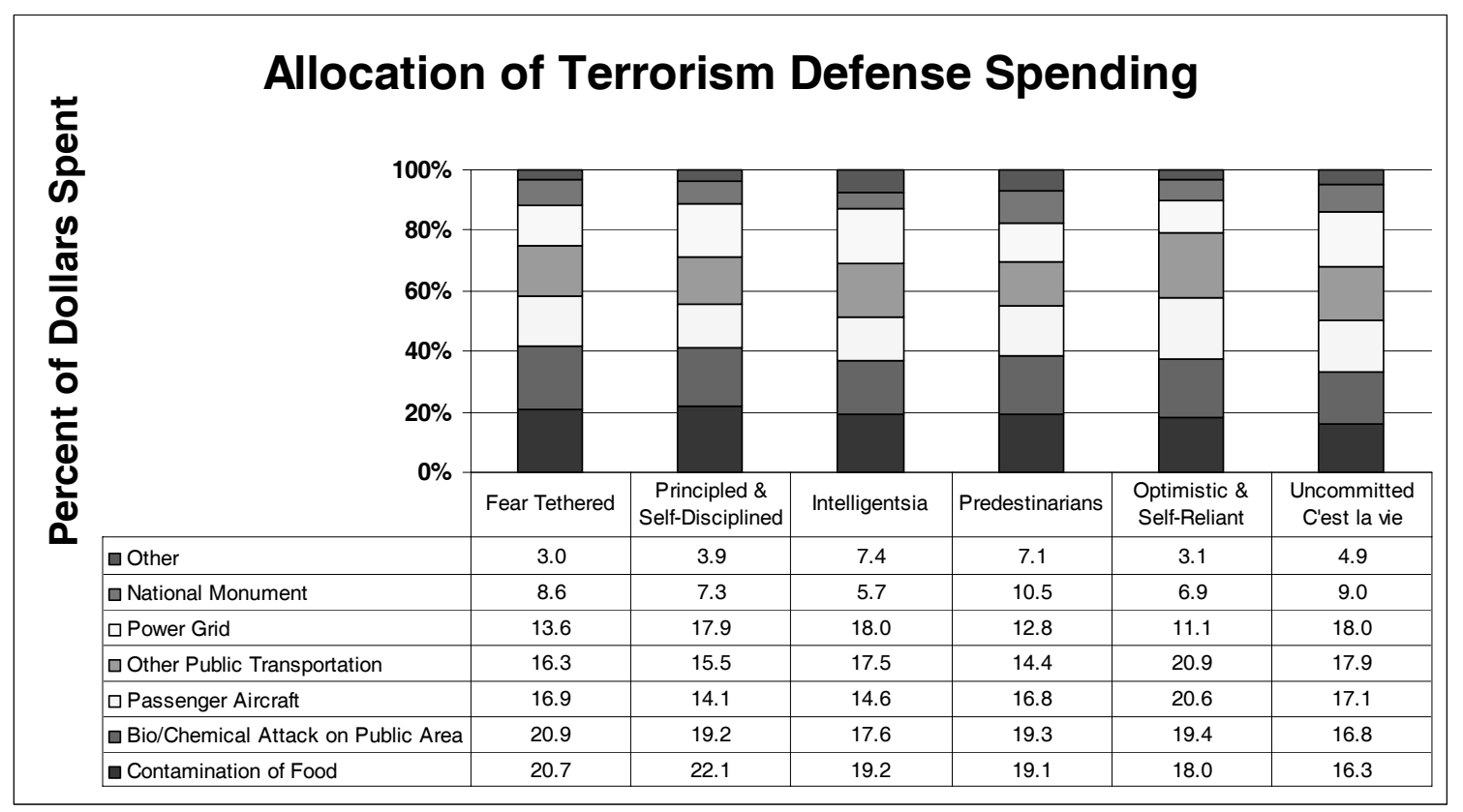

Allocation of defense spending does not vary greatly across archetypes - since the level of concern seems to pertain to terrorism in general. Still some minor differences reflect different interest areas. For example, the "Principled and Self-disciplined" allocated the most (22 percent) for food defense and the "Uncommitted C'est la vie" allocated the least (16 percent). The "Optimistic and Self-reliant" allocated considerably more to transportation modes.

\section{Conclusions:}

Consumers in the United States in 2004 would allocate 13 percent more total dollars to defend the food system than the airline system against terrorist attacks. Based on current spending by the U.S. federal government to protect airline travel, this implies that $\$ 5.65$ billion should be spent to protect the food system compared to the $\$ 93$ million allocated to 
protect the food supply chain in the federal budget year 2007. Private companies are increasing their expenditures and vigilance related to food defense as well. In deciding how to defend the food system and recover after a potential attack, understanding the preferences and behavior of consumers is important. Eliciting consumers' help and helping to educate them as to what they can do in self-defense can minimize the catastrophic impact of a potential attack. Sharing information and defense tactics is in everyone's best interest because food defense is truly a public good from which we all benefit.

\section{Literature Cited:}

Becker, G.S. and Y. Rubinstein (2004) "Fear and the Response to Terrorism: An Economic Analysis" Unpublished manuscript, University of Chicago Department of Economics and School of Economics, Tel-Aviv University.

Kahneman D. and A. Tversky (1979) "Prospect Theory: An Analysis of Decision Under Risk" Econometrica 47 (March): 263-291.

Kennedy, S.P. and F.F. Busta (2006) "Biosecurity - Food Protection and Defense" Chapter 5 in Food Microbiology: Fundamentals and Frontiers, $3^{\text {rd }}$ Edition, M.P. Doyle and L.R. Beuchat, Eds. Washington D.C.: ASM Press (In press)

Kuchler, F. and E. Golan. (2006) "Where Should the Money Go? Aligning Policies with Preferences," Amber Waves, Washington D.C.: USDA, ERS, 4:3, June, pp 31-37.

Lowrance, W.W. (1976) Of Acceptable Risk: Science and Determination of Safety, Los Altos, CA: William Kaufman.

Stinson T., J. Kinsey, D.. Degeneffe and K. Ghosh (2006) "How Should America's Anti-Terrorism Budget Be Allocated? Findings from a National Survey of Attitudes of U.S. Residents" Working paper 01-06: The Food Industry Center, University of Minnesota, http://foodindustrycenter.umn.edu 